

\section{Teste de associação de palavras: Instrumento qualitativo de análise de suas concepções estudiantis}

\section{Test de asociación de palabras: Un instrumento cualitativo de análisis de las concepciones de los estudiantes}

\section{Word Association Test - A Qualitative Tool to Analyze Students' Concepts}

Edimar Eder Batista ${ }^{1}$

Rosana Figueiredo Salvi²

\section{Resumo}

Analisar as concepções de campo e cidade de alunos moradores de áreas rurais e urbanas por meio de um teste de associação de palavras, segundo a abordagem qualitativa e a técnica de análise de conteúdo de Bardin (2011) constitui o objetivo deste artigo. Para respaldar o estudo, abordam-se as relações entre campo e cidade e a palavra, no contexto da formação conceitual, sob a perspectiva socioconstrutivista vigotskiana. Constataram-se semelhanças e distinções nas formas de conceber os espaços rurais e urbanos de cada estudante, que são idiossincráticas. Espera-se que o trabalho contribua para a prática docente de professores da Educação Básica, principalmente de Geografia, que atuam em escolas que atendem a alunos de áreas rurais e urbanas.

\section{Palavras-chave}

campo; cidade;

palavras; concepções;

alunos

1 Professor da Educação Básica do estado do Paraná

2 Professora da Universidade Estadual de Londrina. 


\section{Palabras clave}

campo; ciudad; palabras; concepciones; estudiantes

Keywords

country; city; words; concepts; students

\section{Resumen}

El objetivo de este artículo es analizar los conceptos de estudiantes de zonas rurales y urbanas a través de un examen de asociación de palabras, según enfoque cualitativo y la técnica de análisis de contenido de Bardin (2011). Para apoyar el estudio se analiza la relación entre campo y ciudad y la palabra en el contexto de la formación conceptual de la teoría vigotskiana del constructivismo. Se observaron semejanzas y diferencias en los conceptos de los espacios rurales y urbanos de cada estudiante, que son idiosincrásicos. Se espera contribuir a la práctica de la enseñanza de los maestros de Educación Básica, principalmente de geografía, que trabajan en escuelas en zonas rurales y urbanas.

\section{Abstract}

This paper attempts to examine the concepts of students from both rural and urban areas through a word association test, with a qualitative approach and using Bardin's content analysis technique (2011). The study relies upon the analysis of the relationship between country and city, and words in the context of concept formation, as stated by Vygotsky in the framework of his social constructivism. Idiosyncratic similarities and distinctions in students' concepts of rural and urban areas were observed. This paper is expected to contribute of geography teachers' practice, mainly those working in both rural and urban schools. 


\section{Introdução}

Considerando a existência de conceitos cotidianos e científicos e suas inter-relações (Cavalcanti, 2005; Vigotski, 1993), estando os primeiros associados ao senso comum e os segundos ao aprendizado escolar; a organização das práticas e atividades de ensino-aprendizagem deve contemplar as concepções dos alunos, visto que estes possuem conhecimentos acerca de determinados assuntos abordados em sua escolarização, no caso, sobre o campo e a cidade.

No intuito de analisar as concepções de alunos moradores de áreas rurais e urbanas acerca do campo e da cidade, pautando-se na abordagem qualitativa e na técnica da análise de conteúdo de Bardin (2011), utilizou-se um teste de associação de palavras como instrumento de coleta de dados.

A investigação das concepções de campo e cidade dos estudantes justifica-se em razão de constituir-se, no âmbito do ensino-aprendizagem de Geografia, uma análise de conceitos menos pesquisados em relação à paisagem, território, lugar, e região, por exemplo. Além disso, campo e cidade, por representarem lugares de vivência, são espaços nos quais a percepção dos mesmos pode ser mais palpável que tal apreensão em relação aos outros conceitos geográficos citados.

Este trabalho estrutura-se em duas partes. Para a apreciação das informações advindas deste teste de associação de palavras, realiza-se, primeiramente, uma breve contextualização teórica a respeito das relações entre campo e cidade; das interações entre pensamento e linguagem, no tocante à formação conceitual, na perspectiva vigotskiana; da pesquisa qualitativa e da análise de conteúdo.

Posteriormente, analisam-se as concepções dos alunos, expressas em suas palavras por meio dos testes de associação de palavras de seis estudantes, procurando entender as formas de pensar destes.

\section{Campo, cidade e suas relações}

Como a análise das concepções dos alunos sobre campo e cidade realizou-se por meio das palavras apontadas por estes como relacionadas a estes espaços, apreciar as conotações dos significados destas é pertinente. Considerando a questão etimológica, há relações entre as palavras cidadão, civilidade e cidade; civilidade, civilização e civilizar são conceitos que denotam qualidades de polidez, cortesia, boa educação, e estabelecem hierarquias legitimando a superioridade dos cidadãos moradores das cidades - sobre os demais - os rústicos, rudes, a plebe e o campesinato - no sentido de representar o alto grau de evolução social de um grupo ou sociedade e a ação transformadora do barbarismo à civilização (Bagli, 2006).
Pode-se conceber que o campo é caracterizado por uma realidade antagônica à da cidade, na qual, os espaços rurais e seus modos de vida passaram a ser relacionados ao atraso enquanto a cidade e o modo de vida urbano passaram a ser relacionados ao novo, ao moderno. A substituição da ruralidade pela urbanidade, conforme a autora citada foi considerada como um processo de civilizatório do campo.

O processo de industrialização, iniciado no século XVIII em território europeu, contribuiu para ampliar as associações do campo ao atraso e da cidade ao progresso e para a atração populacional exercida por esta. O rápido crescimento das cidades industrializadas com a contribuição dos grandes fluxos populacionais do campo gerou e gera problemas urbanos ligados à falta de infraestrutura e planejamento adequados ao ritmo deste crescimento.

Atrelado às problemáticas de falta de planejamento urbano para receber os grandes contingentes populacionais vindos do campo surge, paulatinamente, um processo de idealização da vida rural e do campo como um lugar de vida natural, tranquilo e repleto de belezas. 0 romantismo baseava-se na ideia obsessiva de recuperar a unidade perdida entre homem e natureza. Em contraposição, à vida nas cidades passou a ser associada ao caos, à ambição, aos problemas sociais, fortalecendo a visão dicotômica, contrapondo a viciosidade da cidade à virtuosidade do campo (Bagli, 2006).

Willians (2011) constata uma associação da cidade a uma sensação de ilimitadas possibilidades de encontro e movimento, mas também de isolamento e de intranquilidade e, do campo, a uma idealização, no sentido de volta ao passado, na qual, além da ideia de um passado mais feliz havia a ideia de inocência rural, destacando que, em relação ao campo, "talvez o que se celebre seja uma concepção de sociedade rural em contraposição às pressões de uma nova era” (Willians, 2011, p. 55) Ou seja, a idealização do campo seria uma espécie de fuga ao processo de industrialização.

No Brasil também ocorre este processo de valorização da cidade e do urbano em detrimento do rural. Em nosso país, como as áreas rurais são aquelas que se encontram fora dos limites das cidades, o acesso à infraestrutura e serviços básicos é atribuído ao urbano. Cria-se, segundo Abramovay (2000) um vício de raciocínio na maneira como se definem as áreas rurais no território brasileiro que contribui para que estas sejam assimiladas automaticamente ao atraso, carência de serviços e falta de cidadania.

Os teóricos ligados à Educação do Campo também constatam a primazia da cidade e do urbano em detrimento do campo e do rural, inclusive na esfera política, "sistematicamente o campo vem sendo desqualificado como espaço de prioridade para políticas públicas" (Fernandes et al, 2004, p. 40). Segundo Fernandes (2004) é preciso ver o campo como parte do mundo, e não apenas como aquilo que sobra além das cidades. 
A separação entre a cidade e o campo toma lugar entre as primeiras e fundamentais divisões sociais e territoriais do trabalho, grosso modo, trabalho manual no campo e trabalho intelectual na cidade (Lefebvre, 2001; Spósito, 2010). A constituição destes dois espaços distintos entre si é condição, e consequência do estabelecimento da divisão social do trabalho e das relações de poder que o sustentam, nas quais a cidade é marcada pela concentração, espaço propício à realização de atividades que requerem encontro, proximidade ou possibilidade de comunicação, especialização e complementaridade de papéis e funções, enquanto o campo caracteriza-se pela extensão e dispersão atendendo, técnica e economicamente, ao desempenho de outras atividades (Spósito, 2010).

A urbanização, vista por Lefebvre (2001) como um processo ideológico e abstrato, permite que se encontre em suas concepções elementos de permanência da ruralidade em meio ao processo global de urbanização e de industrialização. Por exemplo, este autor considera que a cidade se situa entre uma ordem próxima e uma ordem distante. Entre as relações dos indivíduos organizados em grupos mais ou menos estruturados e a ordem da sociedade, regida por grandes e poderosas instituições como a Igreja e o Estado e por um código jurídico que pode ser formalizado por uma cultura.

Uma interpretação possivel a partir destas concepções lefebvrianas é a de que a ordem distante abstrata, formal e dotada de poderes se projeta na/sobre a ordem próxima que a encarna, projeta-a sobre um terreno, o lugar, e sobre um plano, o plano da vida imediata. Esta ordem próxima não reflete a ordem distante na transparência, ela subordina assim o imediato através das mediações, ela não se entrega.

A questão da intensidade com que o urbano atinge, influencia ou se apodera do rural, constitui uma das inquietações que deram origem à pesquisa abordada parcialmente neste artigo, cujos alunos participantes e o recorte espacial são tratados a seguir.

\section{Os sujeitos e o recorte espacial da pesquisa}

Participaram da pesquisa vinte e nove alunos de três turmas do $3^{\circ}$ Ano do Ensino Médio -duas do período matutino e uma do período noturno- de dois colégios estaduais: o Colégio Estadual Profa. Maria Cintra de Alcântara, localizado na área urbana do município de Tamarana e o Colégio Estadual Profa. Maria Helena Davatz, localizado na área urbana do distrito de Lerroville, município de Londrina, que atendem tanto alunos de áreas urbanas quanto de áreas rurais. Na Figura 1 visualiza-se a localização destes dois municípios e o recorte espacial da pesquisa.

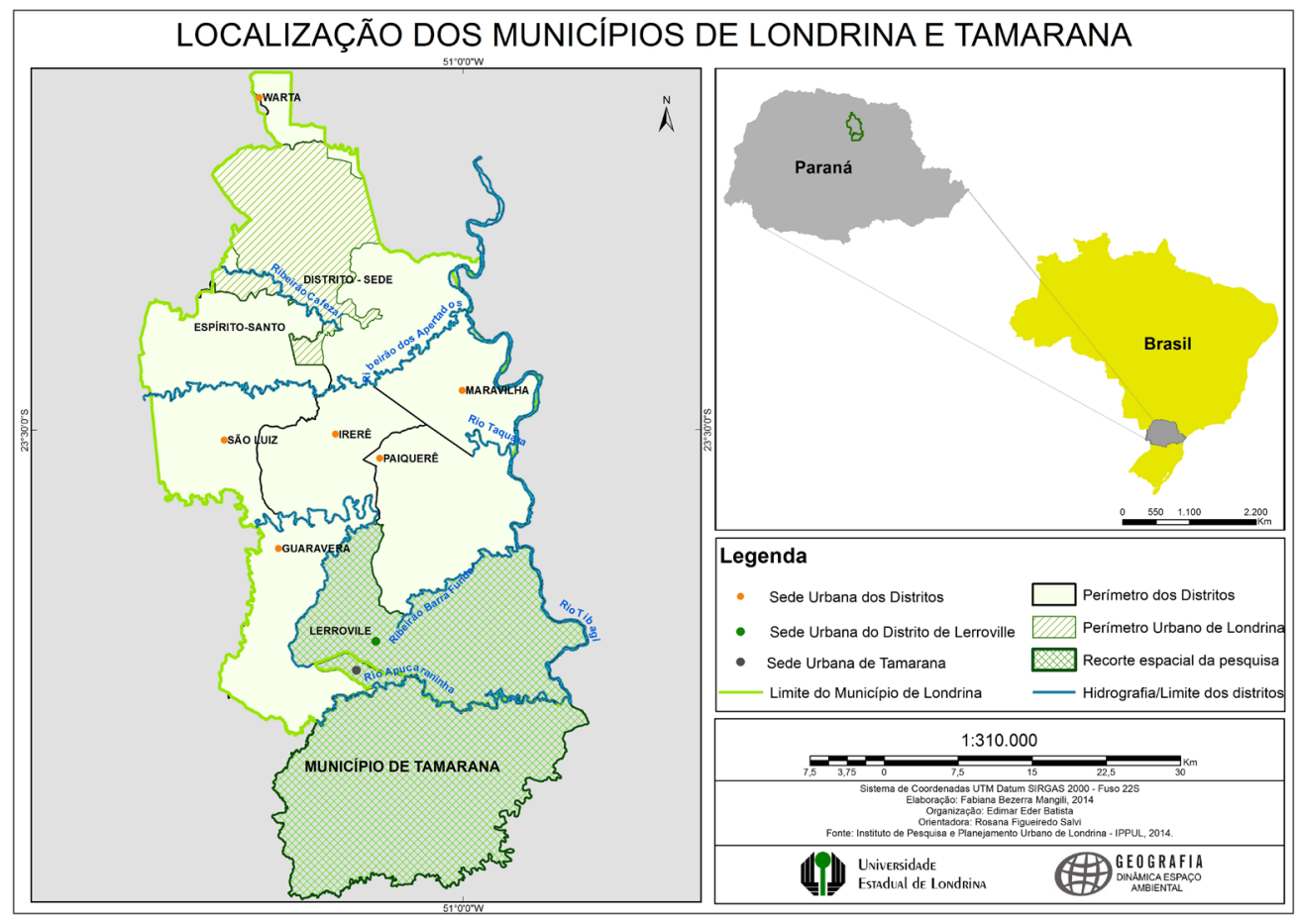

Figura 1. Localização dos municípios de Londrina e Tamarana Fonte: Batista, 2014 
Destaca-se que os referidos município e distrito possuem população rural maior que a população urbana. Segundo dados do Censo Demográfico de 2010 do Instituto Brasileiro de Geografia e Estatística (IBGE), Tamarana tinha população rural de 6.404 e população urbana de 5.848 e Lerroville, 2.102 e 1.673 respectivamente.

Estes alunos, por residirem em áreas rurais e em áreas urbanas com pequeno contingente populacional, próximas a uma grande área urbana, a cidade de Londrina, possuem identidades e inserções distintas em relação às dinâmicas socioeconômicas e culturais rurais e urbanas.

O recorte espacial da pesquisa, portanto, permite que se procure investigar o quanto o urbano está presente nas concepções dos alunos enquanto ordem distante -em razão de sua virtualidade- (veiculação e valorização/afirmação do modo de vida e da cultura urbanas nos meios de telecomunicações, por exemplo) e enquanto ordem próxima -em razão de sua materialidade- presente na proximidade com Londrina, uma das maiores cidades da Região Sul do Brasil e nas áreas urbanas de Tamarana e Lerroville.

A análise das concepções dos alunos realiza-se por meio de suas palavras, concebendo-as como dotadas de generalização e significação. Para tanto, expõe-se a seguir alguns elementos acerca da teoria socioconstrutivista e das ideias vigotskianas.

\section{Palavras no contexto sócio constructivista Vigotskiano}

O entendimento de que os processos de aprendizagem e de formação conceitual nutrem-se mutuamente e de que ambos não ocorrem somente na escola, mas ao longo da vida do ser humano norteia o presente estudo.

Considerando-se que o aprendizado está presente na vida do ser humano desde seu nascimento, ocorrendo, portanto, tanto na escola como fora dela, esta pesquisa utiliza a teoria socioconstrutivista enquanto norteadora da busca da compreensão das interações entre os homens e o mundo que os cerca enquanto propiciadoras do aprendizado e da construção do conhecimento.

Conforme esta teoria o foco da aprendizagem deve estar no aluno, que possui conhecimentos anteriores aos saberes escolares, por isso, considera-se que a aprendizagem tem caráter subjetivo e depende também da motivação do aluno, apesar da necessária mediação docente.

Nesta perspectiva pedagógica o objetivo maior do ensino é a construção do conhecimento mediante o processo de aprendizagem do aluno, que se caracteriza pelo fato de que as funções mentais superiores do homem (percepção, memória, pensamento) desenvolvem-se na sua relação com o meio sociocultural, mediada por signos. O pensamento, o desenvolvimento mental e a própria capacidade de conhecer o mundo é uma construção social que depende das relações do homem com o meio social (Cavalcanti, 1998).

A presente pesquisa centra-se no aluno, assim, concebe-se o "[...] aluno como sujeito do conhecimento, e por isso, protagonista do seu fazer-pensar, qualquer que seja este, agrade ou não, preencha ou não as competências cognitivas que dele se espera" (Kimura, 2008, p. 67). Trabalhar com o senso comum ou com as concepções dos alunos é, portanto, fundamental quando se concebe a existência de uma unidade entre os mesmos e a aprendizagem escolar de cada educando, que é idiossincrática.

Analisam-se as palavras dos alunos enquanto expressão de seu pensamento. Sobre o papel da palavra no processo de formação conceitual, uma das ideias básicas da teoria de Vigotski (1993) é a do caráter histórico e social dos processos psicológicos superiores dentre os quais é possível citar o desenvolvimento da linguagem e da escrita. Este autor considera que a palavra é o signo que serve tanto para indicar um objeto quanto para representá-lo como conceito, sendo assim também um instrumento do pensamento (Cavalcanti, 2005). A palavra contém um significado, e expressa, pois, uma generalização e um conceito. Com o tempo seus significados e sua relação com o pensamento mudam pelo convívio cotidiano fora e dentro da escola, por intermédio das práticas escolares, nas quais as possibilidades do desenvolvimento do pensamento dependem da qualidade dos instrumentos mediadores, dentre os quais se destaca a linguagem (Cavalcanti, 1998).

A palavra constitui-se em um tipo primário de conceito, sendo fundamental para a formação de conceitos na medida em que produz uma generalização da realidade (Couto, 2005). 0 conceito forma-se mediante uma operação intelectual que é dirigida pelo uso das palavras como meio para centrar ativamente a atenção, abstrair sintetizar e simbolizar determinados traços por meio de um signo (Vigotski, 1993).

O cerne das concepções de Vigotski (1993) acerca das palavras no contexto da formação conceitual pode ser assim expresso:

- as palavras representam uma generalização; como seus significados evoluem com o passar do tempo, generalizações de tipo mais primitivo são substituídas por generalizações de um tipo mais elevado, levando à formação dos verdadeiros conceitos;

- o signo, que constitui o meio básico para dominar e dirigir as funções psíquicas superiores, na formação de conceitos, é a palavra, que neste processo desempenha o papel de meio, e posteriormente, torna-se símbolo do mesmo. 
A análise destas concepções com foco na compreensão da construção do significado das palavras permite que se vislumbrem alguns elementos dos processos de expressividade das mesmas, em relação ao pensamento, na fala e na escrita.

Considerando a construção do significado das palavras uma generalização, Vigotski (1993) aponta que para a criança a palavra é uma propriedade do objeto, mais do que um símbolo deste. A descoberta e a consolidação de sua função como signo ocorre somente após a operação com a palavra enquanto propriedade dos objetos.

A palavra é definida por Vigotski (1993) como a união viva entre som e significado. Ao constatar que é no significado da palavra que pensamento e fala se unem em pensamento verbal, entende que as respostas sobre as questões concernentes à relação entre pensamento e fala podem ser encontradas no significado.

O significado é um ato do pensamento, no sentido pleno do termo. Mas, ao mesmo tempo, o significado é parte inalienável da palavra como tal, e dessa forma pertence tanto ao domínio da linguagem quanto ao domínio do pensamento. Uma palavra sem significado é um som vazio, que não mais faz parte da fala humana (Vigotski, 1993, p. 4).

Sem o significado - uma reflexão generalizada da realidade - não existe a verdadeira comunicação, que em suas formas mais elevadas, somente é possível porque o pensamento humano reflete uma realidade conceitualizada. Como o pensamento tem que passar primeiro pelos significados e depois pelas palavras, o entendimento da fala do outro prescinde além do entendimento de suas palavras, a compreensão de seu pensamento. Neste sentido, a palavra é um microcosmo da consciência humana (Vigotski, 1993).

Concebendo os significados das palavras como formações dinâmicas, Vigotski (1993) entende que quando ocorre a mudança de significado, "Não é simplesmente o conteúdo de uma palavra que se altera, mas o próprio modo pelo qual a realidade é generalizada e refletida em uma palavra" (p. 105).

Além do significado, a palavra possui sentidos. Vigotski (1993) atribui a Paulham a distinção entre sentido e significado ao afirmar que:

Segundo ele, o sentido de uma palavra é a soma de todos os eventos psicológicos que a palavra desperta em nossa consciência. É um todo complexo, fluído e dinâmico, que tem várias zonas de estabilidade desigual. 0 significado é apenas uma das zonas do sentido, a mais estável e precisa. Uma palavra adquire o seu sentido no contexto em que surge; em contextos diferentes, altera o seu sentido. 0 significado permanece estável ao longo de todas as alterações do sentido. 0 significado dicionarizado de uma palavra nada mais é do que uma pedra no edifício do sentido, não passa de uma potencialidade que se realiza de formas diversas na fala. [...] Segundo Paulham, o sentido de uma palavra é um fenômeno complexo, móvel e variado, modifica-se de acordo com as situações e a mente que o utiliza, sendo quase ilimitado (Vigotski, 1993, p. 125-126).

Uma palavra pode possuir, portanto, vários sentidos, mas bem poucos ou apenas um significado, que representa uma concepção comum, compartilhada por pessoas possuidoras de uma mesma língua e de concepções ou valores culturais semelhantes. Conforme Vigotski (1993), a partir de determinado contexto, o sentido confere um enriquecimento às palavras.

Para que exista a compreensão entre os interlocutores de uma comunicação, esta deve basear-se, portanto, nos significados e não nos sentidos das palavras. Significados compartilhados permitem, pois, a expressividade do pensamento. Quando os interlocutores não possuem significados comuns para as palavras que utilizam a comunicação é bastante prejudicada.

Considerando-se, pois, os processos de aprendizagem e a expressividade dos pensamentos por meio das palavras como particulares a cada indivíduo, a pesquisa qualitativa apresenta-se como a perspectiva metodológica escolhida para a análise em questão.

\section{A pesquisa qualitativa no cenário da investigação}

Compreende-se que a investigação da aprendizagem de cada aluno é única, singular, sendo a abordagem qualitativa pertinente à análise do caráter idiossincrático da aprendizagem de um grupo de alunos.

Concebe-se que a Metodologia Científica, conforme Goldemberg (1999) envolve algo maior que as regras de como fazer uma pesquisa, auxilia a reflexão e a procura de um novo olhar sobre o mundo, um olhar científico, indagador, curioso, criativo, estando o pesquisador, numa pesquisa científica em busca também do jogo criativo de aprender como pensar e olhar cientificamente em busca de um aprimoramento cognitivo/intelectual e, portanto, humano.

Na pesquisa qualitativa pesquisador e participantes da pesquisa são vistos como sujeitos dotados de conhecimentos que são singulares, podendo ser, pois, complementares ou contraditórios.

O participante da pesquisa qualitativa - no caso o aluno- possui assim quase que um papel de "co-autor" desta. Esta proposta investigativa centra-se no aluno, em suas concepções, conhecimentos, por compreender, conforme Goldemberg (1999) que como a realidade social aparece somente sob a forma como os indivíduos vêem o mundo, a maneira mais adequada do pesquisador captar e realidade é ver o mundo por meio dos olhos dos seus pesquisados. 
A técnica qualitativa empregada para a análise das concepções dos alunos nesta pesquisa é análise de conteúdo, conforme Bardin (2011). Com a explosão da comunicação característica de nossos dias tornou-se imperativo a compreensão para além dos significados imediatos desta, por meio das palavras, imagens, textos e discursos. A descrição e interpretação de opiniões, estereótipos e representações individuais e sociais o recurso da análise de conteúdo parece útil (Bardin, 2011). Sua finalidade é explicar e sistematizar o conteúdo da mensagem e o significado desse conteúdo, por meio de deduções lógicas, tendo como referência quem a emitiu, seu contexto e efeitos (Oliveira et al, 2003).

Pode-se considerar a análise de conteúdo como:

Um conjunto de técnicas de análise das comunicações visando obter por procedimentos sistemáticos e objetivos de descrição do conteúdo das mensagens indicadores (quantitativos ou não) que permitam a inferência de conhecimentos relativos às condições de produção/recepção (variáveis inferidas) dessas mensagens (Bardin, 2011, p. 48).

Com estas técnicas pretende-se que concepções implícitas do produtor da mensagem sejam perseguidas. A duplicidade da tentativa do analista do conteúdo de uma comunicação abrange a compreensão do sentido desta, bem como, de outras significações implícitas possíveis, que figuram ao lado da mensagem primeira. "A leitura efetuada pelo analista, do conteúdo das comunicações, não é, ou não é unicamente, uma leitura "a letra", mas antes o realçar de um sentido que figura em segundo plano" (Bardin, 2011, p. 47).

Conforme a autora o objetivo da análise de conteúdo é a manipulação da mensagem - no sentido de seu conteúdo e da expressão deste - para evidenciar os indicadores que permitam inferir sobre uma outra realidade que não a da mensagem, revelando elementos de ordem psicológica, sociológica, histórica, dentre outros.

Em linhas gerais, a análise de conteúdo objetiva o estabelecimento de um programa de análise preciso, por meio da sistematização de ideias. No presente estudo, utilizou-se como instrumento de coleta de dados, um teste de associação de palavras, com base em Bardin (2011), e procedeu-se a separação e o agrupamento das palavras dele oriundas como forma de analisá-las em conjunto, possibilitando a busca de semelhanças e distinções nas concepções dos alunos participantes do mesmo.
A organização dos dados em gráficos e figuras que condensam e põe em relevo as informações fornecidas pela exploração do material, objetiva torná-los significativos, "falantes" e válidos. Segundo Bardin (2011) a partir de resultados significativos e fiéis o analista pode propor inferências, por meio da qual a análise de conteúdo ultrapassa o alcance descritivo, possibilitando interpretações concernentes aos objetivos da análise ou a descobertas inesperadas e também que se possa regressar a causas e efeitos das características da comunicação.

Neste artigo, tecem-se algumas considerações gerais a respeito das concepções acerca do campo, da cidade e de suas relações, dos vinte e nove alunos participantes da pesquisa, contudo, analisam-se os testes de associação de seis alunos de maneira pormenorizada, no intuito de oportunizar ao leitor o entendimento do processo investigativo deste instrumento de coleta de dados. Salienta-se, no entanto, que o tratamento gráfico destes seis testes de associação de palavras apresentado neste estudo realizou-se exclusivamente para o mesmo.

Tecidas estas considerações teóricas acerca do campo, da cidade e de suas relações expressas em palavras e das perspectivas qualitativas que embasam este estudo, analisa-se a seguir as concepções dos alunos.

\section{As palavras dos alunos e sus concepções de campo e cidade}

Nesta parte do texto, explicita-se a organização das palavras provenientes do teste de associação de palavras realizada na Dissertação, bem como, explora-se outras possibilidades de sistematização e análise deste material, que não foram contempladas na mesma.

A aplicação do teste de associação de palavras objetivou fornecer um conjunto de informações acerca das concepções dos alunos em relação ao campo e a cidade passíveis de um estudo sistematizado, via análise de conteúdo. $O$ registro de preenchimento por um dos alunos pode ser visualizado na Figura 2. 


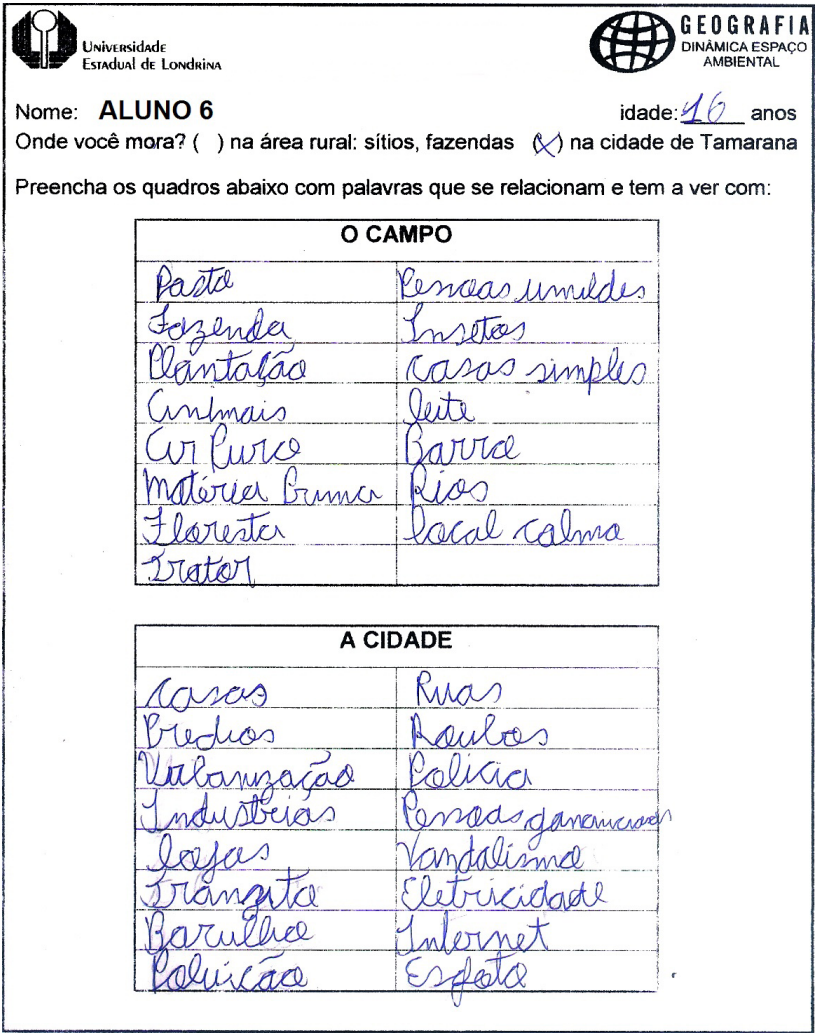

Figura 2. Registro do teste de associação de palavras do Aluno 6 Fonte: pesquisa empírica

$\mathrm{Na}$ análise das palavras provenientes deste instrumento de coleta de dados procedeu-se da seguinte forma: tomando-as em conjunto procurou-se separá-las e agrupá-las com base em seus significados distintos e comuns, observando distinções e semelhanças presentes tanto para aquelas relacionadas à cidade quanto para aquelas relacionadas ao campo.

Construíram-se assim, seis grupos capazes de englobar as diversidades e similaridades dos significados das palavras, sob o âmbito geográfico, a saber:

- Elementos naturais e questões ambientais: abrangendo palavras relacionadas a elementos socioambientais, tais como, árvores, poluição, rios;

- Atributos simbólicos: abrangendo palavras associadas a características, a simbologia, tais como, barulho, tecnologia, tranquilidade;

- Serviços, instituições e locais de uso comum: englobando palavras ligadas à presença de instituições e serviços públicos, serviços em geral e espaços públicos, tais como, escola, mercado, praça;
- Infraestrutura e organização espacial: abarcando palavras relacionadas a elementos concernentes às modificações realizadas no espaço e sua organização, tais como, asfalto, estradas sítios;

- Mobilidade espacial: abrangendo palavras associadas aos deslocamentos espaciais, tais como, carros, difícil locomoção, trânsito;

- Atividades produtivas: englobando palavras relacionadas aos processos produtivos, tais como, indústria, plantações, trator.

A análise deste conjunto de palavras realizou-se em duas etapas. Primeiramente elas foram tomadas em sua totalidade, permitindo que fossem tecidas considerações mais generalizantes acerca dos vinte e nove alunos, em seguida analisou-se as mesmas de maneira mais específica por meio da comparação das palavras de seis alunos.

O Gráfico 1 apresenta a distribuição da totalidade de palavras escritas pelos vinte e nove alunos entre os seis agrupamentos citados. Nele, predominam as palavras relacionadas ao campo ligadas ao grupo das Atividades produtivas e aos Elementos naturais e questões ambientais, tendo destaque também as associadas a Atributos simbólicos deste espaço. No grupo Infraestrutura e organização espacial aparece um número de palavras bem menor se comparado aos grupos de Atividades produtivas, Elementos naturais e questões ambientais e Atributos simbólicos, contudo, superior à Mobilidade espacial e aos Serviços, instituições e locais de uso comum. O que a ocorrência das palavras demonstra?

Uma leitura possível é que as palavras situadas nos grupos Atividades produtivas e Elementos naturais e questões ambientais são atributos praticamente idiossincráticos dos espaços rurais, do campo; ao passo que palavras ligadas aos grupos Mobilidade espacial e Serviços, instituições e locais de uso comum, são praticamente estranhas aos alunos, assim como a percepção da presença de Infraestrutura e organização espacial.

Sob o ponto de vista dos teóricos ligados à Educação do Campo a situação expressa por este conjunto de informações, de que os espaços rurais caracterizam-se pela quase inexistência de infraestrutura e da presença do Estado, explica-se em razão do campo ter sido ou estar sendo concebido como espaço não englobado pelos avanços da sociedade urbano-industrial. Nesse caso, é possível inferir que as aulas de Geografia podem ser mais enfáticas sobre tal problemática, uma vez que a concepção trazida nas palavras escritas pelos alunos carece de alternativas científicas por estarem pautadas no nível do senso comum. 


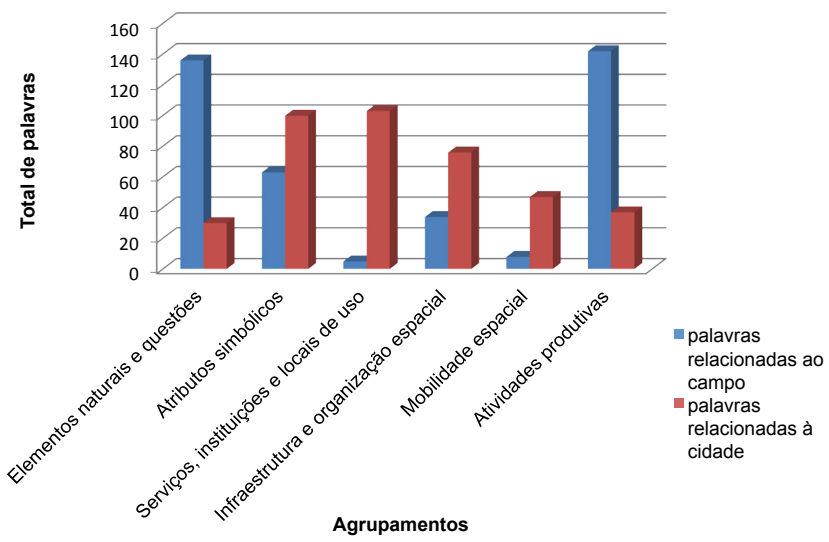

Gráfico 1. Frequência das palavras relacionadas ao campo e a cidade Fonte: Adaptado de Batista, 2014.

Na quantidade de palavras acerca da cidade, no Gráfico 1, observa-se, sobretudo, a predominância de palavras associadas aos grupos de Serviços, instituições e locais de uso comum e Atributos simbólicos, seguida daquelas agrupadas em Infraestrutura e organização espacial. Mobilidade espacial, atividades produtivas e Elementos naturais e questões ambientais apresentaram ocorrência inferior de palavras se comparadas aos três primeiros agrupamentos citados.

O Atributo simbólico é um grupo marcante enquanto característica da cidade, também concebida como espaço dotado de Serviços, instituições e locais de uso comum e de Infraestrutura e organização espacial. Mesmo não tendo a mesma significância, os grupos Mobilidade espacial, Atividades produtivas e Elementos naturais e questão ambiental são presentes. Pode-se inferir que as aulas de Geografia acentuam e caracterizam melhor a cidade que o campo, dado que as palavras dos alunos refletem uma abrangência de elementos ligados aos seis grupos capazes de englobar diversidades e similaridades dos significados sob o âmbito geográfico.

As palavras associadas à cidade apresentam, quanto aos agrupamentos de maior ocorrência, significativa distinção em relação às associadas ao campo. Há certo equilíbrio entre o número de palavras dos seis agrupamentos, não havendo, como no campo, percepção de ausência de algum deles.

As palavras dos alunos, em conjunto, demonstram que campo e cidade são espaços concebidos de formas distintas. Enquanto o primeiro caracteriza-se como espaço natural e de produção agropecuária no qual a mobilidade espacial é reduzida, com setor de serviços e presença do Estado praticamente ausentes; a segunda qualifica-se como espaço simbólico onde a presença do Estado é percebida na organização espacial por meio da infraestrutura e dos serviços públicos, no qual a mobilidade espacial tem destaque.
Após estas considerações acerca da totalidade das palavras dos vinte e nove alunos, realiza-se uma análise mais específica dos conjuntos de palavras de seis estudantes a fim de demonstrar como se procedeu a separação e o agrupamento das mesmas, refletir sobre a forma de pensar os espaços rurais e urbanos de cada um, comparando-os.

As figuras 3, 4 e 5 apresentadas a seguir são compostas por uma legenda referente aos seis agrupamentos de palavras e por dois testes de associação de palavras, nos quais cada palavra é identificada por uma cor que a referencia a um determinado agrupamento.

Palavras compostas, como "produtos industrializados", por exemplo, são concebidas como uma palavra. As palavras que se consideraram pertencentes a dois agrupamentos possuem duas cores, o que não significa que o agrupamento não possua grau de generalidade satisfatório, mas que algumas palavras possuem significações mais amplas em relação à maioria dos outros termos.

$\mathrm{Na}$ Figura 3, observam-se semelhanças entre as concepções do Aluno 13 e do Aluno 26, para os quais o campo é concebido como um espaço produtivo, marcado também pelos elementos naturais e ambientais e pelos atributos simbólicos. As palavras "matéria-prima" e "animais livres" foram consideradas pelos dois alunos como relacionadas ao campo e as palavras "ar limpo" e "sem poluição" utilizadas para referirem-se a este espaço possuem semelhanças. No entanto, constata-se que o Aluno 13 possui uma concepção de campo mais idílica em relação ao Aluno 26 que cita aspectos negativos deste espaço como roubo de animais e desmatamento. 0 primeiro aluno viveu dois anos no campo durante a sua infância, enquanto o segundo sempre viveu na área rural.

Quanto à cidade, da análise da Figura 3 percebe-se que este espaço é primordialmente simbólico para os dois alunos. Entretanto, o Aluno 26 o concebe sob um prisma mais negativo que o Aluno 13. As palavras "tecnologia" e "poluição" são utilizadas pelos dois estudantes e "animais presos" " "animais domesticados" são bastante semelhantes, assim como as palavras "controle das atividades" " "carga horária" que sugerem rigidez nas relações de trabalho urbanas.

As distinções nas concepções de dois alunos que sempre viveram em áreas urbanas são apresentadas na Figura 4, na qual, para o Aluno 20 campo é marcado pelas atividades produtivas e secundariamente pelos elementos naturais, enquanto para o Aluno 12 ocorre o inverso: este espaço é primordialmente natural e ambiental, e também produtivo. As palavras do primeiro representam elementos concretos, como, "bois", "trator", "árvores", as do segundo referem-se principalmente a elementos abstratos, como, "produtividade", "salário", "habitat natural", estando os atributos simbólicos mais presentes entre as palavras do Aluno 12. Não existem palavras iguais ou semelhantes dos dois estudantes para o espaço rural. 
Em relação à cidade, na Figura 4, enquanto para o Aluno 2 este espaço é marcado pela presença de elementos associados aos serviços públicos, ao setor de serviços em geral, à infraestrutura e organização espacial, para o Aluno 12, o espaço urbano é primordialmente simbólico, corrobo- rando a constatação do parágrafo anterior de que as palavras do Aluno 2 referem-se principalmente a elementos concretos, ao passo que, as do Aluno 12 a elementos abstratos. "Hospitais" é a única palavra comum aos dois estudantes para a cidade.

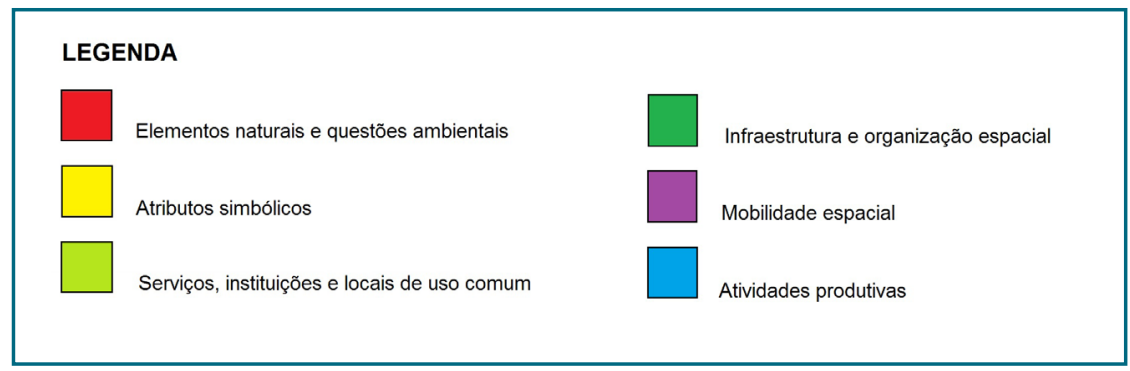

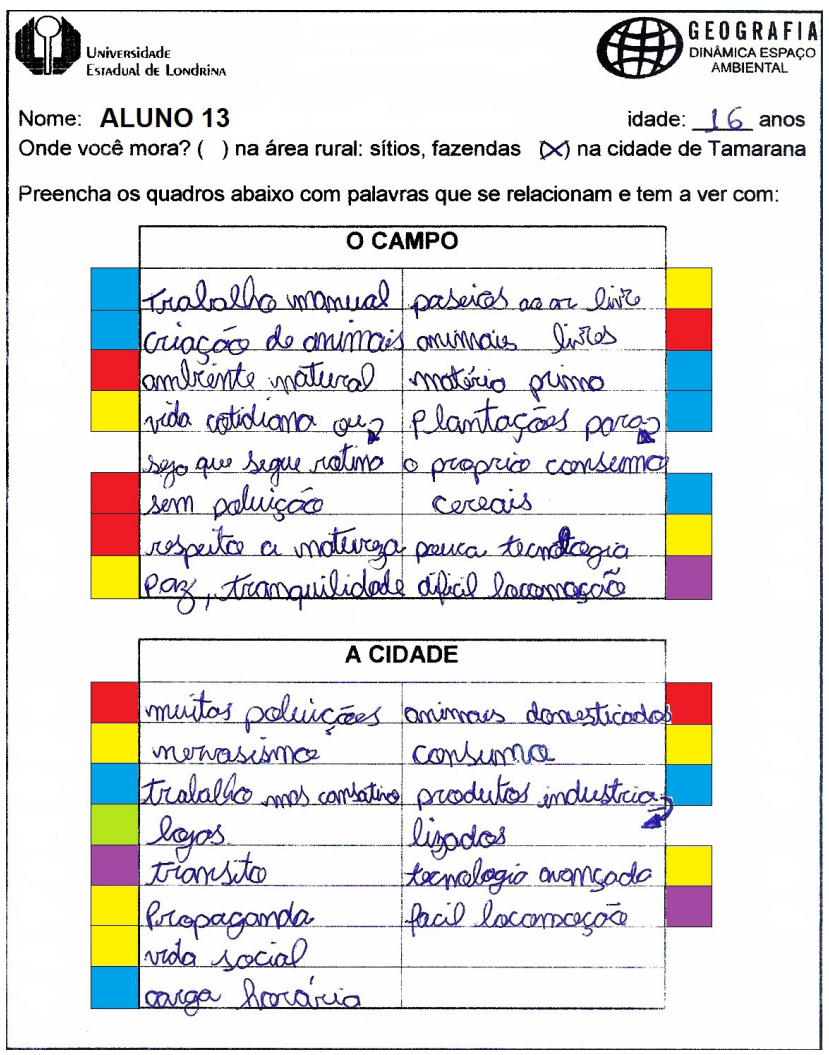

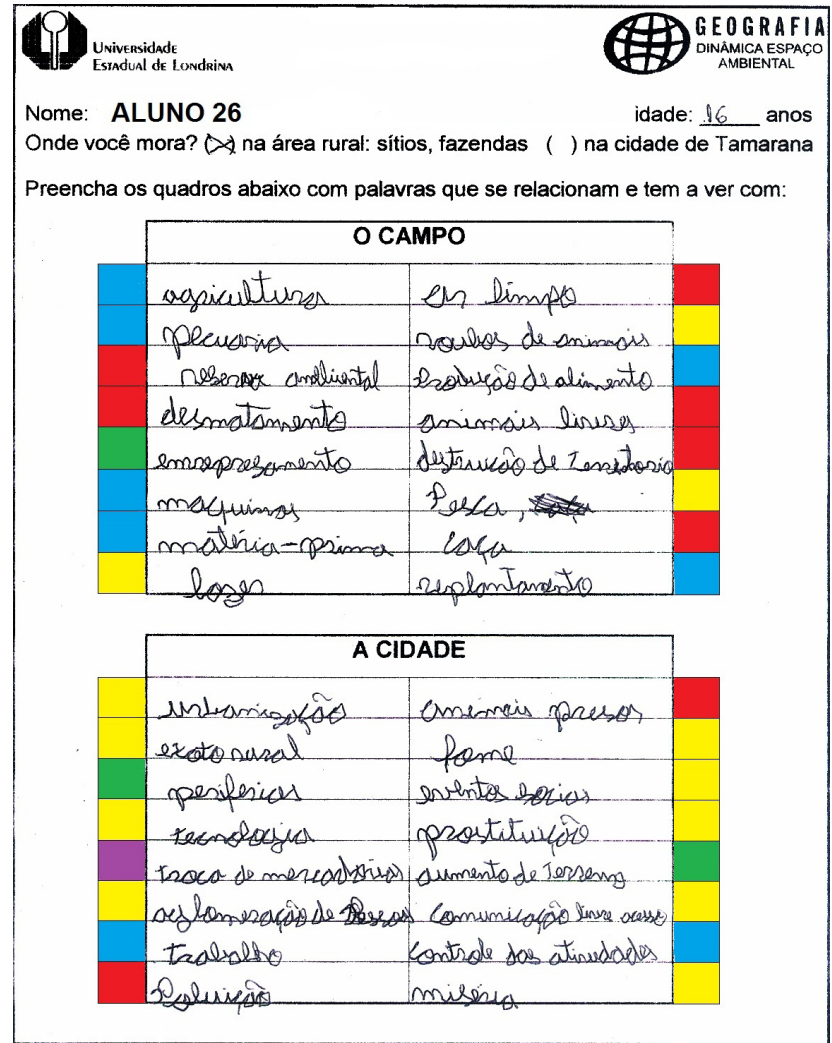

Figura 3. Semelhanças entre as concepções de campo e cidade do Aluno 13 que vive em área urbana, mas já viveu em áreas rurais e do Aluno 26 que sempre viveu em áreas rurais

Fonte: pesquisa empírica 


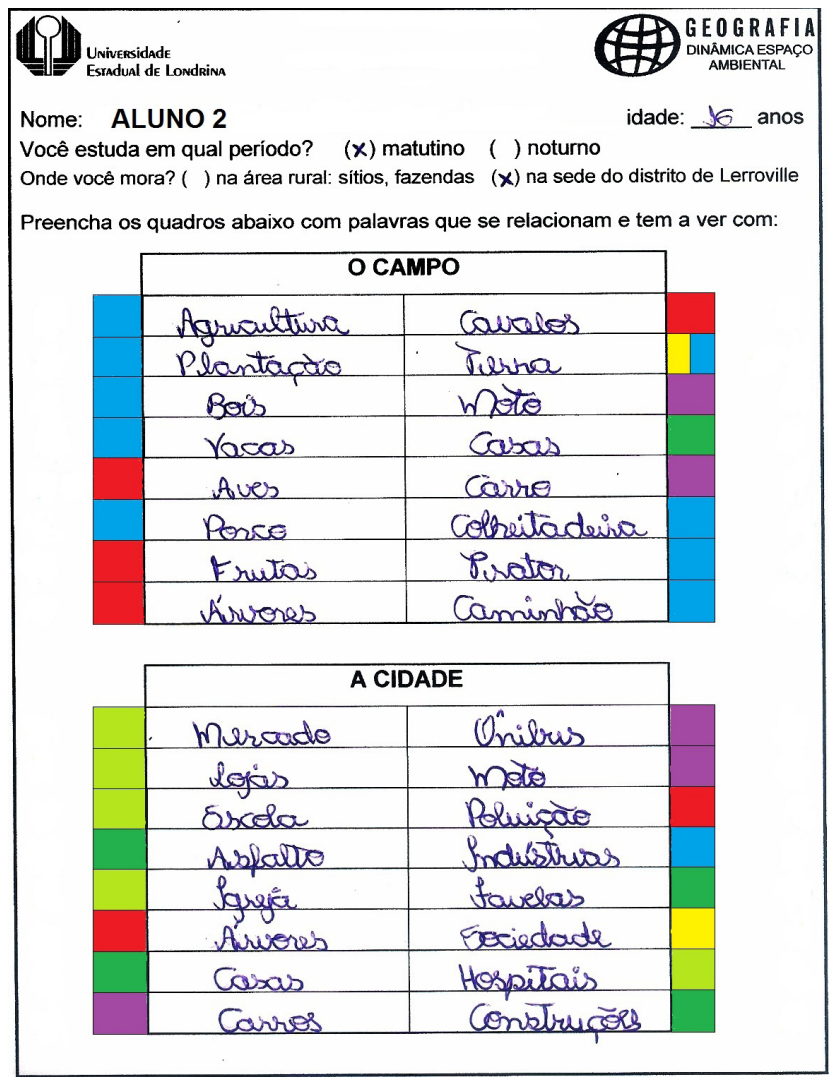

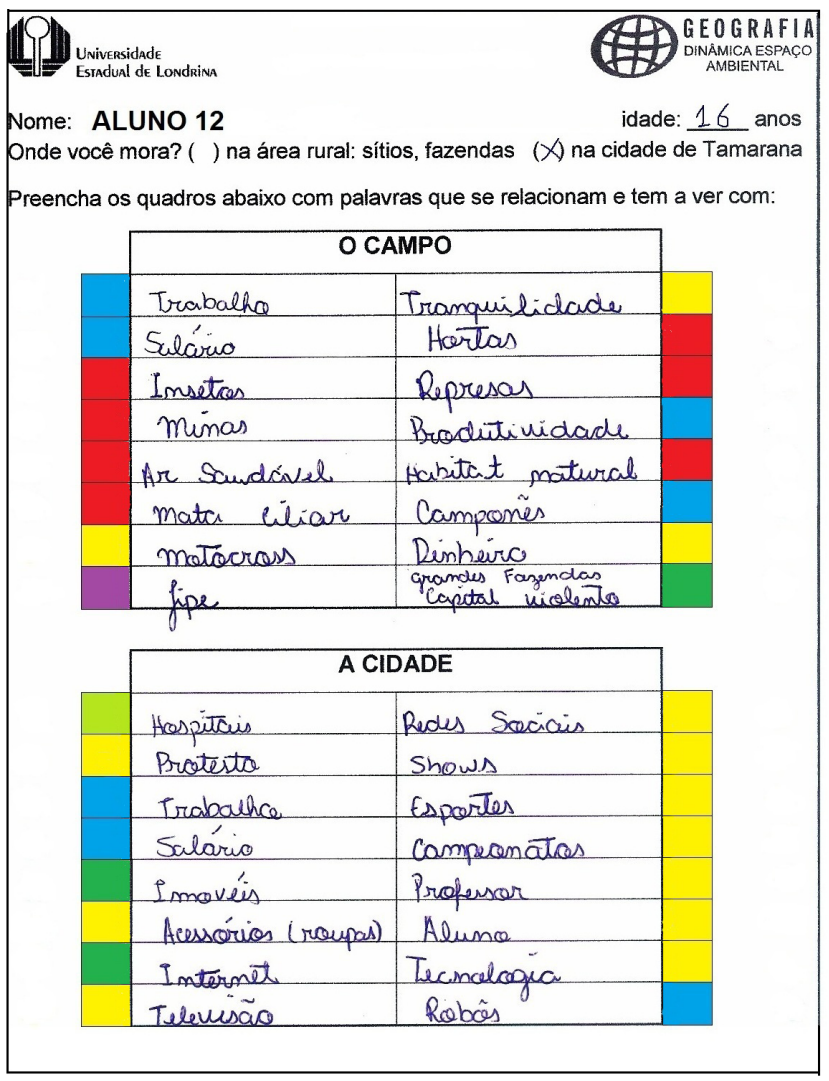

Figura 4. Distinções entre as concepções de campo e cidade do Aluno 2 e do Aluno 12 que sempre viveram em áreas urbanas Fonte: pesquisa empírica

Distinções e semelhanças nas concepções de dois alunos que sempre viveram em áreas urbanas podem ser visualizadas na Figura 5, na qual, embora os agrupamentos de palavras predominantes nos espaços rurais e urbanos sejam distintos, verificam-se várias palavras comuns aos dois estudantes. Enquanto para o Aluno 4 o campo é caracterizado pelos elementos naturais e atributos simbólicos, para o Aluno 10 o é pelas atividades produtivas e pela infraestrutura e organização espacial. As palavras comuns a este espaço são "plantações", "cerca", "estradas de terra" e "arvores".

Quanto à cidade, na Figura 5, há semelhanças nas concepções dos estudantes, sendo este espaço marcado pela infraestrutura e organização espacial e pela presença do setor de serviços e instituições públicas. São comuns aos dois alunos as palavras "asfalto", "muros", "prédios" e "viaduto(s)".
Dos seis alunos cujas palavras foram analisadas, um sempre viveu no campo, o Aluno 26, o Aluno 13 residiu por dois anos em áreas rurais, os Alunos 10 e 12 sempre viveram em áreas urbanas, mas são filhos de agricultores e os Alunos 2 e 4 sempre residiram em áreas urbanas. As diferenças nas concepções dos mesmos podem ser atribuídas aos distintos vínculos com os espaços rurais e com áreas urbanas de maior porte, como Londrina, por exemplo. Já as palavras que denotam semelhanças nas formas de pensar o campo e a cidade, além de estarem presentes no dia a dia dos estudantes, provavelmente compuseram o discurso escolar acerca destes espaços. As palavras de cada aluno em conjunto, demonstram que a forma de pensar, de conceber os espaços rurais e urbanos é idiossincrática. 


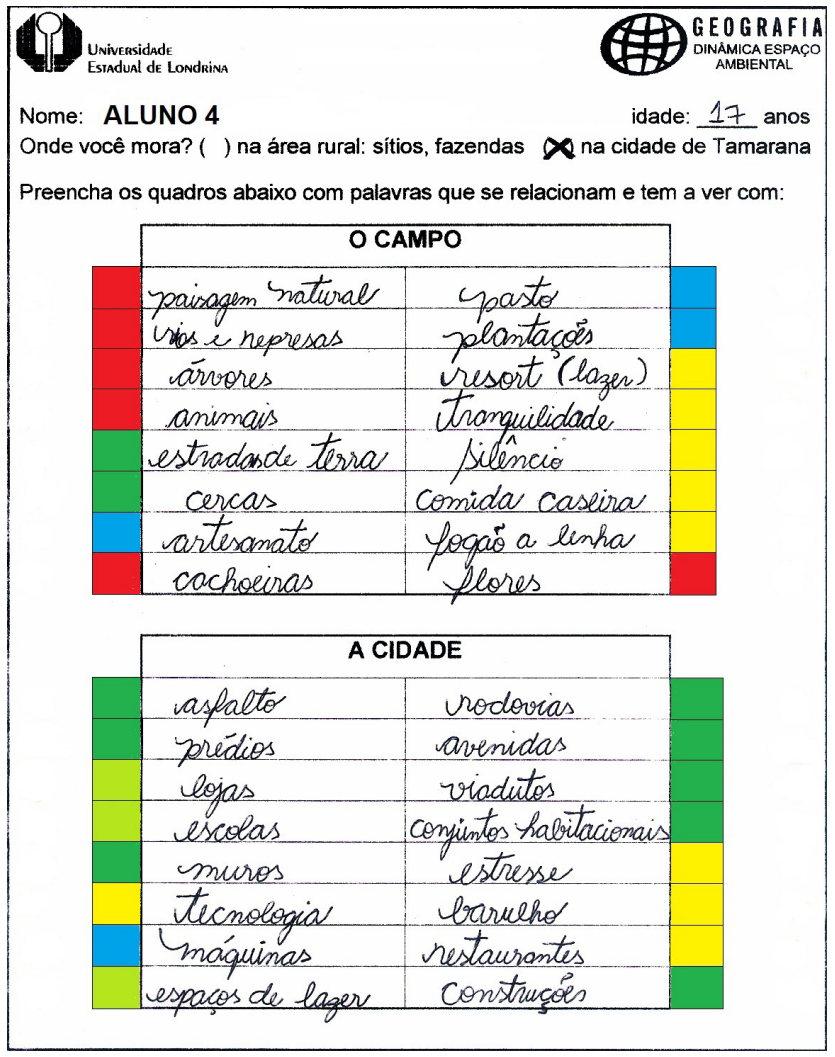

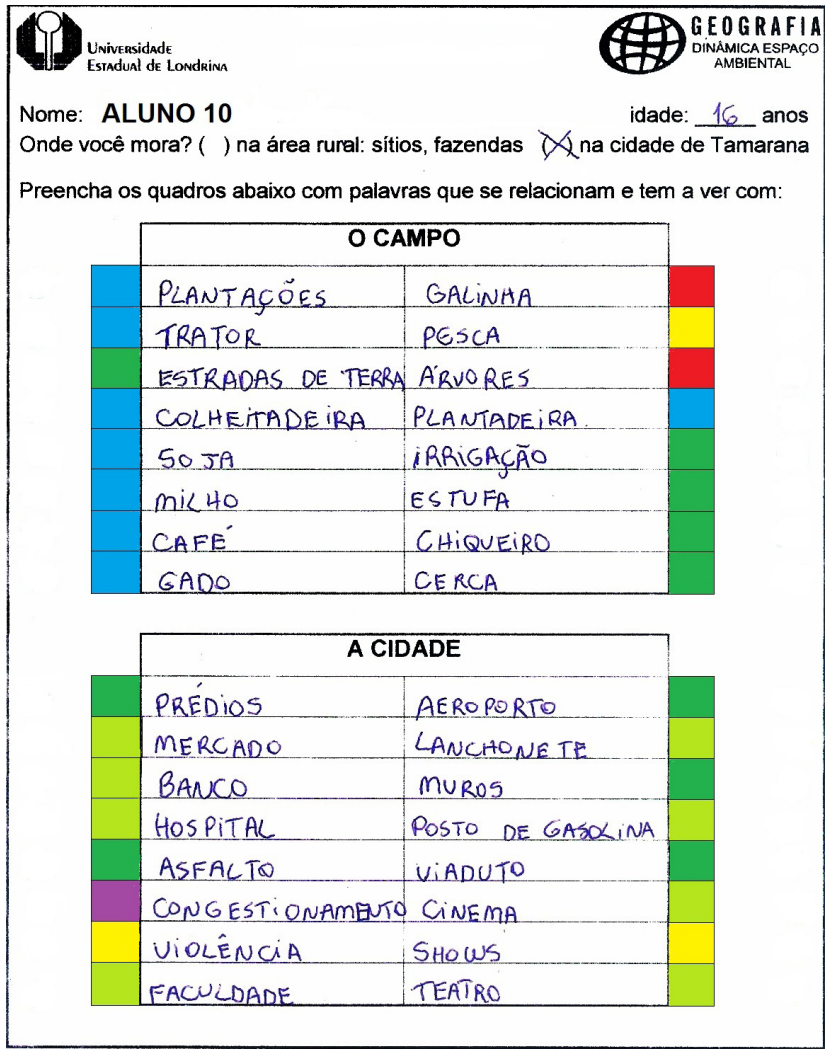

Figura 5. Distinções e semelhanças entre as concepções de campo e cidade do Aluno 4 e do Aluno 10 que sempre viveram em áreas urbanas Fonte: pesquisa empírica

\section{Considerações finais}

A análise da distribuição das palavras em relação aos seis agrupamentos propostos possibilitou a identificação tanto de aspectos similares quanto distintos nas concepções dos alunos em relação aos espaços rurais e urbanos. Portanto, o teste de associação de palavras mostrou-se um instrumento de coleta de dados capaz de distinguir concepções de campo e cidade dos estudantes quando associada à técnica qualitativa de análise de conteúdo.

Campo e cidade são concebidos como espaços distintos pelo total de alunos participantes da pesquisa. Enquanto o primeiro é associado aos elementos naturais e às atividades produtivas, o segundo relaciona-se aos atributos simbólicos, à presença de serviços e instituições públicas e de infraestrutura, denotando a percepção da presença do Estado nos espaços urbanos e de sua ausência nos espaços rurais.
A análise pormenorizada dos conjuntos de palavras dos seis estudantes demonstrou que, embora haja semelhanças advindas da escolarização e da vivência em contextos socioespaciais similares, a forma de pensar os espaços rurais e urbanos é singular a cada aluno.

Os resultados deste trabalho podem contribuir para que professores de Geografia da Educação Básica que atuem em escolas com alunos de áreas rurais e urbanas pensem suas estratégias de ensino-aprendizagem em relação ao campo e a cidade considerando os conhecimentos que os estudantes já possuem acerca destes espaços e a relevância da escolarização na construção dos mesmos. 


\section{Referências bibliográficas}

Abramovay, R. (2000). Funções e medidas da ruralidade no desenvolvimento contemporâneo. Texto para discussão, 702, 1-31. Disponível em: http://www.ipea.gov.br/portal/images/stories/PDFs/ TDs/td_0702.pdf

Arroyo, Miguel G. et al. (2004). Apresentação. In: Arroyo, Miguel G. et al. (Orgs.). Por uma educação do campo (pp. 7-18). 2. ed. Petrópolis: Vozes.

Bagli, P. (2006). Rural e urbano nos municípios de Presidente Prudente, Álvares Machado e Mirante do Paranapanema: dos mitos pretéritos às recentes transformações. Dissertação (Mestrado em Geografia) - Presidente Prudente, SP: UNESP.

Bardin, L. Análise de conteúdo. (2011). (Luís A. Reto, trad.). São Paulo: Edições 70.

Batista, E. E. (2014). Análise de concepções de campo e de cidade de alunos de áreas rurais e urbanas e a aprendizagem geográfica. $314 \mathrm{f}$. Dissertação (Mestrado em Geografia) - Universidade Estadual de Londrina, Londrina.

Cavalcanti, L. de S. (1998). Geografia, escola e construção de conhecimentos. Campinas: Papirus.

Cavalcanti, L. de S. (2005, mai-ago). Cotidiano, mediação pedagógica e formação de conceitos: uma contribuição de Vygotsky ao ensino de Geografia. Cadernos Cedes, 25 (66), 185-207.

Couto, M. A. C. (2005). Pensar por conceitos geográficos. In: Castelar, Sônia. (Org.). Educação geográfica: teorias e práticas docentes (pp. 79-96). São Paulo: Contexto.

Fernandes, B. M. (2004). Diretrizes de uma caminhada. In: Arroyo, Miguel G. et al. (Orgs.). Por uma educação do campo (pp. 133-145). 2 ed. Petrópolis: Vozes.

Fernandes, B. M. et al. (2004). Primeira Conferência Nacional Por uma Educação Básica do Campo" (texto preparatório). In: Arroyo, Miguel G. et al. (Orgs.). Por uma educação do campo. (pp. 19-63). 2 ed. Petrópolis: Vozes.

Goldenberg, M. (1999). A arte de pesquisar: como fazer pesquisa qualitativa em ciências sociais. 3. ed. Rio de Janeiro: Record.

Kimura, S. (2008). Geografia no ensino básico: questões e propostas. São Paulo: Contexto.
Lefebvre, H. (2001). O direito à cidade. (R. E. Frias, trad.). São Paulo: Centauro.

Oliveira, E. de. et al. (2003 mai-ago). Análise de conteúdo e pesquisa na área da educação. Revista Diálogo Educacional, 4 (9), 11-27.

Spósito, M. E. B. A (2010). questão cidade-campo: perspectivas a partir da cidade. In: M. E. B.spósito, et al. (Orgs.). Cidade e campo: relações e contradições entre o urbano e o rural (pp.111-130). 2. ed. São Paulo: Expressão Popular.

Vigotski, L. S. (1993). Pensamento e linguagem. (Jeferson L. Camargo, trad.). São Paulo: Martins Fontes.

Willians, R. (2011). O campo e a cidade: na história e na literatura. (P. H. Brito, trad.). São Paulo: Companhia das Letras. 